\title{
Consumer testing of the preliminary paediatric food-based dietary guidelines for healthy children aged 1-7 years, among English- and Afrikaans-speaking mothers in the city of Cape Town, South Africa
}

\author{
Lesley Dalene Scott ${ }^{1, *}$, Debbi Marais ${ }^{1}$ and Lesley Bourne ${ }^{2}$ \\ 'Division of Human Nutrition, Faculty of Health Sciences, Stellenbosch University and Tygerberg Academic \\ Hospital, Tygerberg 7505, South Africa: ${ }^{2}$ Environment \& Health Unit, South African Medical Research Council, \\ Tygerberg 7505, South Africa
}

Submitted 22 November 2007: Accepted 7 July 2008: First published online 2 September 2008

\begin{abstract}
Objective: The aim of this qualitative study was to test the comprehensibility of the preliminary food-based dietary guidelines (FBDG) for healthy South African children aged 1-7 years. Objectives included assessing exposure to FBDG, comprehension of the proposed paediatric FBDG (PFBDG) and whether the guidelines can be used in meal planning.

Design: Focus group discussions were used to collect data. Discussions were facilitated by the investigator in either English or Afrikaans, according to a predetermined discussion schedule. Focus groups were formed on the basis of language and socio-economic status (SES).

Setting: Areas within the City of Cape Town representing lower, middle and upper SES groups.

Subjects: A total of seventy-six English- and Afrikaans-speaking mothers were contacted via randomly selected consenting preschool groups to participate voluntarily. Results: Most mothers reported that they do not use guidelines. They had a good grasp of the concepts of and need for PFBDG. They suggested slight alterations to wording/phrasing of the guidelines. The most problematic guidelines were those regarding starch, milk and sweet treats/drinks. No substantial differences were found between English and Afrikaans data. Differences were found between SES groups, with the upper SES groups comprehending the guidelines better. Conclusion: The proposed PFBDG were well received. The target population that would benefit the most from these guidelines would be the less educated, lower SES groups. The present study shows that once the guidelines have been modified, they may be used as a comprehensive guide for nutritional education.
\end{abstract}

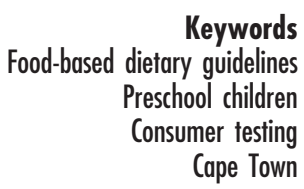

The Nutrition Society of South Africa initiated the formation of the South African Food-Based Dietary Guidelines (FBDG) Working Group in 1997 following the recommendations made by the FAO and the WHO to provide country-specific dietary guidelines ${ }^{(1,2)}$. FBDG for healthy adults and children over 7 years of age were adopted by the Department of Health in 2003 and the process is described in further detail in the South African Journal of Clinical Nutrition 2001 ${ }^{(2-4)}$. The process of developing modified dietary guidelines for groups with specific dietary needs started in 2000, with the initiation of the Paediatric FBDG (PFBDG) Working Group aimed at developing FBDG for children younger than 7 years ${ }^{(2,4-6)}$. The group members included experts in paediatric nutrition from the Nutrition Directorate, the South African Medical Research Council, Red Cross Children's Hospital, the Universities of Cape Town, Stellenbosch and the Western Cape, as well as the food and private sector hospital industries ${ }^{(7)}$.

As cited by Labadarios et al. ${ }^{(8)}$, over the past two decades numerous studies have shown a relatively high prevalence of malnutrition among South African preschool children. The South African Vitamin A Consultative Group suggested in 1994 that roughly 660000 preschool children were identifiably malnourished ${ }^{(9)}$. According to the more recent National Food Consumption Survey (NFCS), one in ten children aged 1-9 years was underweight and one in five was stunted ${ }^{(8)}$. Overnutrition is a health problem in urban formal housing areas, with one in thirteen children being overweight ${ }^{(8)}$. The working group decided that focus should be placed on lowincome groups, that PFBDG should address under- and 


\section{Box 1 - Preliminary paediatric Food-Based Dietary Guidelines for the 1-7-year-age group}

1. Encourage children to enjoy a variety of foods.

2. Feed children 5 small meals a day.

3. Make starchy foods the basis of a child's main meals.

4. Children need plenty of vegetables and fruits every day.

5. Children need to drink milk every day.

6. Children can eat chicken, fish, meat, eggs, beans, soya or peanut butter every day.

7. If children have sweet treats or drinks, offer small amounts with meals.

8. Offer children clean, safe water regularly.

9. Take children to the clinic every 3 months.

10. Encourage children to be active every day.

overnutrition for apparently healthy children and that they should be used within all sectors of society ${ }^{(4,10,11)}$.

The same WHO/FAO process as used to develop the adult guidelines was used to develop the preliminary PFBDG directed to the child carer $^{(7)}$. Sub-categories within the 0-7-year age group were formed to meet differing dietary needs ${ }^{(2)}$ and consensus was achieved for the age groups of 0-6 months, 6-12 months and 1-7 years. The preliminary PFBDG were formulated based on brainstorming sessions during which the existing South African paediatric burden of nutrition-related disease, published scientific evidence and nutrition policy documentation was taken into account. A set of messages was generated and approved for testing by the Working Group in 2003 and is currently undergoing continuous consumer testing ${ }^{(2,7)}$.

Communication and comprehensibility of FBDG are critical if they are to be understood and applied correctly $^{(1)}$. FBDG are practical, positive messages that are food and not nutrient based. They are brief qualitative statements that address the nutrition-related public health issues of a country, as well as relating to a country's specific socio-cultural context. They therefore encourage a wide range of dietary practices ${ }^{(1)}$.

The aim of the present study was the consumer testing, among English- and Afrikaans-speaking mothers, of the preliminary PFBDG for 'healthy'* children aged 1-7 years, in the City of Cape Town, South Africa (Box 1). Specific objectives included assessing exposure to FBDG, comprehension of the proposed PFBDG and whether they can be used in meal planning.

\section{Method}

Ethics approval was obtained from the Committee for Human Research, Stellenbosch University (Project No. N05/03/046). A qualitative study design was followed

* WHO definition of health: Health is a state of complete physical, mental and social well-being and not merely the absence of disease or infirmity ${ }^{(12)}$. The proposed PFBDG thus exclude low birth weight babies. using focus group discussions to collect data. Some quantitative data were collected using a sociodemographic questionnaire.

The study population was English- and Afrikaansspeaking mothers with 1-7-year-old children, in the City of Cape Town, Western Cape Province, South Africa. Specific suburbs/areas within the City of Cape Town were randomly selected to represent lower, middle and upper SES groups using randomisation tables. The average property value of an area, provided by Knowledge Factory Pty Ltd, was used as a proxy for SES. Focus groups of six to eight women were based on language and SES and conducted within these areas, in places of convenience, with the understanding that data collection could be stopped at saturation point.

With Department of Education's approval, mothers were sampled purposively from randomly selected playgroups, crèches and pre-primary schools in the selected areas. Those facilities granting permission to recruit mothers were given invitations asking mothers to participate voluntarily.

As English and Afrikaans are the most prominent languages spoken in the City of Cape Town ${ }^{(13)}$ and since there were numerous messages to be consumer-tested, it was decided that all messages would be tested, but only in these two languages, using English and Afrikaans guidelines. To reduce bias related to mother tongue language proficiency $v$. second language proficiency of the participants, mothers were asked to take part in the focus group of their mother tongue. Two pilot focus group discussions were conducted in Stellenbosch to assess the appropriateness of the topic guide. Comprehension of the guidelines was assessed by whether the mothers could discuss and phrase back the guidelines in their own words. Exposure to and usefulness were assessed by asking mothers whether they had heard of the guidelines and whether they would use them for meal planning.

Mothers had to meet the following criteria to be included in the study: they had to have healthy children aged 1-7 years, they had to preferably be the only household member who makes food decisions, they had 
Table 1 Participants' characteristics

\begin{tabular}{|c|c|c|c|c|c|c|c|c|c|}
\hline \multirow[b]{2}{*}{ Category } & \multicolumn{3}{|c|}{ Upper SES (n 30) } & \multicolumn{3}{|c|}{ Middle SES ( $n$ 35) } & \multicolumn{3}{|c|}{ Lower SES (n 11) } \\
\hline & $\%$ & Mean & SD & $\%$ & Mean & SD & $\%$ & Mean & SD \\
\hline Average age (years) & & $38 \cdot 4$ & $4 \cdot 8$ & & $36 \cdot 6$ & $7 \cdot 5$ & & $39 \cdot 4$ & $13 \cdot 2$ \\
\hline Language (\%) & & & & & & & & & \\
\hline English & $53 \cdot 3$ & & & $48 \cdot 6$ & & & $54 \cdot 5$ & & \\
\hline Afrikaans & $46 \cdot 7$ & & & $51 \cdot 4$ & & & $45 \cdot 5$ & & \\
\hline$\%$ with metric and/or tertiary education & $90 \cdot 0$ & & & $54 \cdot 3$ & & & $9 \cdot 0$ & & \\
\hline Average number of children & & 2 & 1 & & 2 & 1 & & 2 & 1 \\
\hline Average age of children (years) & & $4 \cdot 6$ & $1 \cdot 6$ & & $4 \cdot 7$ & $1 \cdot 4$ & & $4 \cdot 1$ & $1 \cdot 2$ \\
\hline$\%$ with employment & $66 \cdot 7$ & & & $45 \cdot 71$ & & & $27 \cdot 3$ & & \\
\hline
\end{tabular}

SES, socio-economic status.

to have no formal training in nutrition, and they had to participate willingly.

The investigator started focus group sessions by welcoming the mothers and telling them briefly about the discussion. Participants were given a consent form and a questionnaire asking for basic demographic information such as education level. Once completed, group discussions followed according to a topic guide that asked various questions about the wording and phrasing of each guideline. The investigator facilitated all sessions, which were videotaped for transcription. Each session was planned to be roughly $90 \mathrm{~min}$ long and refreshments were served.

After video recordings were transcribed, content analysis was used to look for group themes relating to the above-mentioned objectives. Themes were previously determined based on data from the pilot study. A statistician from Stellenbosch University acted as a consultant for data analysis as required.

\section{Results}

A total of seventy-six English- and Afrikaans-speaking mothers took part in the focus group discussions. There were six groups in both the upper and middle SES areas, and two groups in the lower SES areas. Participant characteristics are shown in Table 1. No considerable difference was found between English and Afrikaans groups regarding exposure to, comprehension of and ease of using the guidelines, and yet some Afrikaans mothers made use of English terminology. A difference was revealed with regard to SES and maternal level of education. Due to this, classifications as shown in Box 2 will be used.

\section{Exposure to food-based dietary guidelines}

The general response was that mothers do not necessarily use guidelines. Group A and B mothers look to other sources of dietary information such as magazines.

\section{Consumer comprebension of each proposed paediatric food-based dietary guideline}

The following are perceptions of and suggestions made by the mothers, regarding each PFBDG.

\section{Box 2 - Group classifications}

Group A: All upper SES, highly educated groups

Group B: All middle SES, highly and less educated groups

Group C: All lower SES, least educated groups

Encourage children to enjoy a variety of foods

General consensus was that the guideline implies that different foods should be presented to children in an interesting and consistent manner to ensure a balanced diet. None of the groups expressed a desire to have the guideline changed.

\section{Feed children 5 small meals a day}

In all groups, 'small' was understood to imply a 'handful' or a fruit portion, whereas the word 'meal' had connotations of a large plate of nutritious food eaten while seated, or a substantial volume eaten at breakfast, lunch and dinner. Mothers reported that children 'graze throughout the day', generally in the form of three meals and two snacks, which provide sustained energy. Options given for more understandable phrasing included ' 3 meals and 2 snacks' or ' 5 small portions or light meals a day'.

\section{Make starchy foods the basis of a child's main meals}

All mothers understood the term 'starchy foods' and the reason for eating such foods. The more-educated mothers, however, said the term is old-fashioned and that 'carbohydrates', namely high, medium and low GI carbohydrates, should be used instead. They also disagreed that starch should form the basis of main meals, because it is not sustaining and too much may lead to weight issues. Suggestions for more understandable wording were 'Include starch as part of a child's diet', 'Make starch the major component of the meal', or replace 'starch' with 'carbohydrate'.

\section{Children need plenty of vegetables and fruits every day} The mothers agreed with this guideline because it emphasises consumption of vegetables and fruits. They knew these foods are an important source of vitamins, minerals, fibre and natural sugars. Mothers believed that as long as children get either fruit or vegetables during the 
day, there is no need to get both. Mothers felt that the guideline is important because it changes one's mindset about snacking - fruit is nutritionally superior to biscuits. However, affordability was a constraint to this guideline for Group C mothers. Mothers felt that examples should be given and that specific portion quantities would be better understood than 'plenty'.

\section{Children need to drink milk every day}

The responses to this guideline were the most varied, with a great deal of uncertainty regarding the advantages of milk intake. One mother's comment sums up the general consensus expressed: 'I have an uneasy relationship with milk because I don't know whether it's good or bad for you'.

All mothers give milk with tea, milo, hot chocolate or cereal. Mothers understood that it is aimed at ensuring a sufficient calcium intake, yet felt that too much may lead to sinusitis problems and weight gain. Mothers thought the term 'dairy products' would be more appropriate than milk and that the guideline should read something like: 'Children need dairy products, as a source of calcium, every day'. Some would also like a brief mention of milk 'allergy' and 'intolerance' and their symptoms.

Children can eat chicken, fish, meat, eggs, beans, soya or peanut butter every day

All mothers serve their children protein foods, with soya being the least used. All mothers apparently provide eggs, ranging from one a month up to three or six per week. Mothers from Groups A and B try to limit the amount because of the cholesterol content. When asked whether children ate peanut butter, there was an overwhelming positive response that the children have it on sandwiches to playgroup/crèche/pre-primary school almost every day.

Mothers agreed that protein is an important component of the diet because it is involved in growth and development, muscle building and satiety. They thought the guideline to be a sound one because it uses the word 'can' instead of 'must' and protein sources are listed. Alternative suggestions included placing forward slashes between the words e.g. chicken/meat/fish, placing 'fish' at the beginning because omega 3 fatty acids are good, and saying 'Children can eat protein, such as chicken, fish, meat, eggs, beans, soya or peanut butter every day'.

\section{If children have sweet treats or drinks, offer small amounts with meals}

The response here was mostly negative. Mothers felt the word 'with' implies that these should form a part of every meal. Most mothers reported giving some sweet treats or drinks to prevent their children from overindulging at parties. Mothers did feel that moderation is important, and that a fruit or yoghurt can be offered as a sweet alternative.

Reasons for keeping it to a minimum varied: Group A said sweets must not become a standard and must not replace meals; Group B mothers said sweets have a 'low nutritional level', are 'bad for teeth', and they make children fat and 'jumpy'; Group C mothers said sweets cause teeth to rot.

Mention was made of the fact that sweets and carbonated drinks should not be allowed at playgroups/crèches/ pre-primary schools. Options for alternative wording included 'after meals' instead of 'with meals', stopping the sentence after 'small amounts' or 'If children have sweet treats or drinks, offer small amounts occasionally, after nutritious meals'.

\section{Offer children clean, safe water regularly}

The concept of safe, clean water varied within groups, but most mothers understood that water should not be stagnant. Group A and B mothers believed that 1-2 litres of water are required per day, while Group C mothers did not give an amount.

Mothers tend to give pure water or diluted juice, but mentioned that as children grow older, they want less water and more juice or a cool drink. Mothers who drink a lot of water found that their children do the same and those who do not drink water have children who consume almost no water at all.

Mothers were happy with the guideline and expressed the view that teachers should encourage children to drink water. Some suggestions were made for alternative phrasing, such as explaining what clean and safe water is, replacing 'regularly' with 'frequently' and perhaps giving a minimum amount that is required per day.

\section{Take children to the clinic every 3 months}

Mothers agreed with this concept, namely that children should see a health professional while young. They did not, however, think that children need to be taken every 3 months because 'clinics would not be able to accommodate the workload' and queues get too long.

Mothers agreed that children should go to the clinic when they are sick or need to be immunised. Group B mothers felt that check-ups and tuberculosis tests are important. Mothers were not certain about the ages at which immunisations have to be given and want to be told.

Mothers want to be informed that they can ask about developmental information at a clinic. Wording suggestions included 'Take children to the clinic when required' and 'Take your children to the clinic for check-ups and to ask for information about development'.

\section{Encourage children to be active every day}

In all groups, 'active' was understood to involve physical movement and mental stimulation. Mothers felt that if a child is not active, he or she will become lazy and overweight.

Group A and B mothers would like to see preschools allocate time for activity. Mothers mentioned that fine and gross motor skills have to be included in the guideline 
and that mental activity should also be emphasised. Options for alternative wording of the guideline were 'Encourage children to be active every day with a range of fine motor to gross motor activities' and 'Encourage children to be physically active and mentally stimulated every day'.

\section{Usage of paediatric food-based dietary guidelines}

Group A mothers said these guidelines only serve to remind them about what they already know, and therefore felt that they are possibly more suited for less-educated populations. They mentioned that underprivileged groups may have to be re-educated about nutrition because the guidelines may not be aligned with their current cultural practices. They did like the guidelines because they are suggestive and not prescriptive.

Group B mothers reported that the guidelines are useful, but could be more specific regarding recommended quantities and ideas on how to put the guidelines into practice. Group C mothers believed the guidelines to be appropriate and useful. They seemed to understand the concepts of the guidelines, but were often uncertain about their rationale.

\section{Discussion}

It has previously been documented that a child's nutritional status is directly related to the educational level of the caregiver, and malnutrition is often found hand-inhand with a lack of education and resources ${ }^{(8,14)}$. Research also shows that parents strongly influence their children's eating behaviours through creating the right atmosphere, choosing which foods are available, how they are eaten and how much is consumed ${ }^{(15-17,19)}$. According to the NFCS report, only 3\% of mothers in the Western Cape are uneducated ${ }^{(8)}$.

Most of the guidelines were well grasped and seen as beneficial. Three guidelines with which there was substantial dissatisfaction throughout almost all groups were those regarding starch, milk, and sweet treats and drinks. It was mostly the wording of these guidelines that was percieved as ambiguous or problematic. On a positive note, the mothers did see the importance of these guidelines. The research by Goulding et al. ${ }^{(18)}$ reported that children who avoid consuming milk incur more fractures than children who do consume milk. They also reported that when milk is replaced with carbonated drinks, body weight increases and the skeleton becomes weaker, leading to increased fractures ${ }^{(18)}$. Regarding sweet treats and drinks, research exploring parental control has shown that by restricting access to a certain food, a preschool child's attention will simply be drawn to the particular food and as a result will often increase its intake ${ }^{(19,20)}$.

In some cases, mothers expressed the need for quantifiable messages, pictures and more information within the messages; this may be due to how nutrition information has previously been presented. It should be remembered, however, that FBDG are for the consumer and not quantifiable, whereas food goals and guides are. Once the mothers were told that supportive documentation would contain some quantifiable information, such as adequate water intake being estimated as between 1.3 litres and 1.7 litres/d for children aged $1-8$ years $^{(21)}$, they were satisfied with the guidelines being brief.

Regarding the fruit and vegetable guideline, supportive documentation should provide information about the importance of fruit and vegetable consumption to correct the assumption that only fruit or vegetables are needed. As supermarkets are sources of food item purchases, they are areas in which interventions can influence the availability and pricing of fruits and vegetables. Furthermore, they have shown positive effects regarding increased consumption $^{(22,23)}$.

Mothers were in agreement about the importance of the clinic visit guideline. However, the mothers believed that clinics would not be able to accommodate the workload if they took their children to the clinic every 3 months and that queues get too long. These barriers were also reported in Van der Merwe's consumer testing of the proposed PFBDG for 6-12-month-old babies ${ }^{(2)}$. Mothers did want to know more about immunisation, and this should be added to supportive documentation. Davis et $a l^{(24,25)}$ also reported this in the United States.

Most mothers were concerned about their child's level of physical activity and would like to see physical activity brought into preschools. Pate et al. ${ }^{(26)}$ report that physical activity is influenced by the characteristics of the preschool, and therefore preschools should provide facilities for play. In the USA, the National Association for Sport and Physical Education has recently released guidelines on physical activity for preschools ${ }^{(26)}$.

Group A mothers felt that the guidelines would be better suited for the less-educated groups and that they should be re-educated about healthy nutritious eating. Belief systems and cultural aspects do affect food patterns. This was explored by Jain et al. ${ }^{(19)}$ who found that low-income mothers in Ohio were not worried about children being overweight, because large sizes could be seen as desirable in their culture. In South and North Africa, female obesity has also been found to be a sign of fertility and prosperity ${ }^{(27-29)}$.

According to the NFCS, there is a direct correlation between educational level and nutritional status ${ }^{(8)}$. A low educational level is correlated with undernutrition, and a high level of education is related, in some cases, with child overnutrition. ${ }^{(8)}$. The nutrition information of Group A mothers was sometimes misguided or incorrect and thus they may also benefit from using the PFBDG.

All mothers said that the guidelines should be made available in health institutions, playgroups/crèches/preprimary schools, primary schools and secondary schools. 
The media can also be used to reinforce the PFBDG ${ }^{(4)}$. The Integrated Management of Childhood Illnesses, Paediatric Case Management Guidelines and Integrated Nutrition Programme recommendations are implemented at the primary health care level and PFBDG should be integrated with these messages. They should be reviewed regularly to ensure that they are consistent with the dietary recommendations already in place ${ }^{(30)}$.

\section{Conclusion}

Group participants had a good grasp of the concepts of and need for PFBDG. The more-educated participants had a better comprehension of nutrition and so seldom required an explanation for the rationale underlying each guideline. The less-educated mothers tended to respond positively to the guidelines without always understanding their scientific rationale, yet knowing that they are beneficial to health.

Mothers only suggested slight alterations to the guidelines, implying that the guidelines themselves are not too complicated, but that the interpretation of their wording sometimes differs. Mothers thought that the PFBDG could prove to be useful, especially if used as an aid in educating mothers about what foods to feed their children in order for them to get a balanced diet.

Provided the guidelines are modified and presented with additional information, they may play a significant role in educating mothers about a healthy diet for their children. The present study has shown that consumer testing plays a vital role in the development of countryspecific guidelines, and that a single set of comprehensive guidelines may prove to be useful and appropriate.

\section{Recommendations}

As upper SES groups already have a good grasp of basic nutrition information, the target population for interventions aimed at increasing the awareness of PFBDG should be poorly educated mothers from a low SES community. This supports the Paediatric Working Group's decision that the PFBDG should be focused on low-income groups. However, upper SES groups could also potentially benefit from the guidelines with respect to diets that are not balanced, and hence it is necessary to make the guidelines available to all income groups.

As the proposed PFBDG are qualitative, supportive documentation should contain quantitative information for each guideline regarding portion sizes, relevant explanations, pictures, affordable examples and information about vitamins and minerals. The supportive documentation could also be phrased to address possible constraints to applying the advice of the PFBDG. This may help mothers to put the guidelines into practice. Van der Merwe ${ }^{(2)}$ noted in her consumer testing of the PFBDG for children aged 6-12 months that when guidelines were discussed with an explanation of the rationale behind them, they were better understood.

Future strategies should be put into place to make new information available in all of South Africa's official languages. Once approved, an awareness campaign should be instigated to alert the public of the guidelines' importance and availability. It is recommended that all forms of media, or community and school interventions, are used. The investigator agrees with the recommendations made in the NFCS that socio-economic upliftment as well as nutritional and health education can go a long way in improving the nutritional status of a child ${ }^{(8)}$.

Further studies should be planned in lower SES areas and also done in other official languages. Perhaps ongoing testing can be done on a periodic basis to assess how attitudes and needs change regarding food, and how these changes affect the use and interpretation of the PFBDG.

\section{Limitations of the study}

It proved to be difficult to recruit mothers from the upper and lower SES areas. As a result, saturation point could not be reached in the lower SES group. Due to this limitation, the sample was not representative of all the English- and Afrikaans-speaking mothers in the City of Cape Town.

Mothers generally mentioned that they were pressed for time and therefore the sessions had to be conducted in a shorter period than within the allocated time frame. However, this was the case in most of the groups, thereby eliminating any advantage of one group over another.

\section{Acknowledgements}

Sources of funding: The study was funded by South African Medical Research Council.

Conflict of interest: The authors declare that there is no conflict of interest.

Authorship responsibilities: L.D.S. is the corresponding author, did the research and wrote the paper. D.M. and L.B. were study leaders and only advised on the research and the writing.

\section{References}

1. World Health Organization (1998) Preparation and Use of Food-based Dietary Guidelines. Report of a Joint FAO/WHO Consultation. Technical Report Series no. 880. Geneva: WHO.

2. Van der Merwe J (2004) A qualitative assessment of the preliminary Food-based Dietary Guidelines for infants 6-12 months of age in the Greater Oudtshoorn area. Thesis, Stellenbosch University.

3. Nutrition Society of South Africa (1996) Nutrition task teams for South Africa: a new opportunity and challenge. S Afr J Food Sci Nutr 8, 160. 
4. Vorster H, Love P \& Browne C (2001) Development of food-based dietary guidelines for South Africa - the process. S Afr J Clin Nutr 14, Suppl. 3, S3-S6.

5. Nutrition Information Centre of the University of Stellenbosch (2003) The 'silent emergency': childhood undernutrition. http://www.sun.ac.za/nicus (accessed August 2005).

6. World Health Organization (2002) The World Health Report 2002 - Reducing Risks, Promoting Healthy Life. http:// www.who.int/whr/2002 (accessed August 2005).

7. Bourne LT, Marais D \& Love P (2007) The process followed in the development of the paediatric food-based dietary guidelines for South Africa. Matern Child Nutr 3, 239-250.

8. Labadarios D, Steyn N, Maunder E et al. (1999) The national food consumption survey (NFCS) - children aged 1-9 years, South Africa 1999. http://www.saspen.com/ 2001/natfoodsurvey.htm (accessed January 2005).

9. South African Vitamin A Consultative Group (1996) Anthropometric, vitamin A, iron and immunization status in children aged 6-71 months in South Africa, 1994. S Afr Med J 86, 354-357.

10. Love P (2002) Developing and assessing the appropriateness of the preliminary Food-based Dietary Guidelines for South Africans. PhD Thesis, University of Natal.

11. Bowley NA, Pentz-Kluyts MA, Bourne LT \& Marino LV (2007) Feeding the 1 to 7-year old child. A support paper for the South African paediatric food-based dietary guidelines. Matern Child Nutr 3, 281-291.

12. World Health Organisation (1948) WHO definition of Health. http://www.who.int/about/definition/en/ (accessed March 2005).

13. South African Statistics Council (2001) Census 2001. http:// www.statssa.gov.za (accessed August 2005).

14. Delgado HL, Valverde VE, Martorrel R \& Klein RE (1982) Relationship of maternal and infant nutrition to infant growth. Early Hum Dev 6, 273-286.

15. Strauss R (2002) Childhood obesity. Pediatr Clin N Am 49 , 175-201.

16. Lucas B (1999) Normal nutrition from infancy through adolescence. In Handbook of Pediatric Nutrition, 2nd ed. pp. 99-120 [P Queen Samour, K King Helm and CE Lang, editors]. Maryland: Aspen Publishers Inc.

17. Wardle J, Carnell S \& Cooke L (2005) Parental control over feeding and children's fruit and vegetable intake: how are they related? J Am Diet Assoc 105, 227-232.
18. Goulding A, Rockell JEP, Black RE, Grant AM, Jones IE \& Williams SM (2004) Children who avoid drinking cow's milk are at increased risk for prepubertal bone fractures. J Am Diet Assoc 104, 250-253.

19. Jain A, Sherman SN, Chamberlin LA, Carter Y, Powers SW \& Whitaker RC (2001) Why don't low-income mothers worry about their preschoolers being overweight? Pediatrics 107, 1138-1145.

20. Birch LL (2002) Childhood overweight: family environmental factors. Nestlé Nutrition Workshop Series: Pediatric Series 49, 161-173.

21. Bourne LT, Harmse B \& Temple N (2007) Water: a neglected nutrient in the young child? A South African perspective. Matern Child Nutr 3, 303-311.

22. Glanz K \& Yaroch AL (2004) Strategies for increasing fruit and vegetable intake in grocery stores and communities: policy, pricing, and environmental change. Prev Med 39, S75-S80.

23. French SA \& Wechsler H (2004) School-based research and initiatives: fruit and vegetable environment, policy, and pricing workshop. Prev Med 39, 101-107.

24. Davis TC, Fredrickson DD, Kennen EM et al. (2004) Childhood vaccine risk/benefit communication among public health clinics: a time-motion study. Public Health Nurs 21, 228-236.

25. Davis TC, Fredrickson DD, Arnold CL et al. (2001) Childhood vaccine risk/benefit communication in private practice office settings: a national study. Pediatrics 107, e17.

26. Pate RR, Pfeiffer KA, Trost SG, Ziegler P \& Dowda M (2004) Physical activity among children attending preschools. Pediatrics 114, 1258-1263.

27. Mvo Z, Dick J \& Steyn K (1999) Perceptions of overweight women about acceptable body size of women and children. Curationis 22, 27-31.

28. Puoane T, Matwa P, Bradley H \& Hughes G (2006) Sociocultural factors influencing food consumption patterns in an urban township in South Africa. Hum Ecol (Special issue) 14, 89-93.

29. Mokhtar N, Elati J, Chabir R et al. (2001) Symposium: Obesity in developing countries: biological and ecological factors. J Nutr 131, 887S-892S.

30. Hendricks M, Goeiman H \& Dhansay A (2007) Food-based dietary guidelines and nutrition interventions for children at primary healthcare facilities in South Africa. Matern Child Nutr 3, 251-258. 